\title{
Molecular Sequence Variation
}

National Cancer Institute

\section{Source}

National Cancer Institute. Molecular Sequence Variation. NCI Thesaurus. Code C97926.

A variation in or modification of the molecular sequence of a gene or gene product. 